\title{
ARTIGO
}

CO https://doi.org/10.22481/praxisedu.v15i36.5899

\section{ASPECTOS DA VALORIZAÇÃO DOCENTE EM NARRATIVAS DE PROFESSORAS DOS ANOS INICIAIS DO ENSINO FUNDAMENTAL ${ }^{1}$}

ASPECTS OF TEACHERS'S VALORIZATION IN NARRATIVES OF PROFESSIONALS OF THE FIRST YEARS OF ELEMENTARY SCHOOL

\author{
ASPECTOS DE LA VALORIZACION DEL DOCENTE EN RELATOS DE PROFESORAS \\ DE LOS PRIMEROS AÑOS DE LA ENSEÑANZA FUNDAMENTAL
}

Valdete Aparecida Fernandes Moutinho Gomes Universidade Federal de Ouro Preto - Brasil

Célia Maria Fernandes Nunes Universidade Federal de Ouro Preto - Brasil

Karla Cunha Pádua

Universidade do Estado de Minas Gerais - Brasil

\begin{abstract}
Resumo: A valorização docente tem sido, recorrentemente, enfatizada pelos profissionais e estudiosos da área educacional como um dos aspectos mais importantes para a construção de uma sociedade mais democrática e para a qualidade da educação. Com base nesse pressuposto, apresentamos resultados de uma pesquisa de mestrado cujo objetivo consistiu em investigar a valorização docente, a partir de narrativas de professoras dos anos iniciais do ensino fundamental da rede municipal de Mariana, Minas Gerais, em diálogo com referenciais teóricos sobre a temática. Constatamos que o conceito de valorização docente é polissêmico, envolve aspectos objetivos (formação, remuneração, condições de trabalho e carreira) e subjetivos (reconhecimento social e a realização profissional) e que ambos encontram-se imbricados na vida do/a professor/a. Com base nas narrativas das professoras pesquisadas, apontamos outros aspectos envolvidos nas condições de trabalho, para além das conquistas alcançadas no município, como a elevação salarial proporcionada pelo plano de carreira. Dessa forma, abordamos questões pouco exploradas nos estudos sobre a temática tais como: as relações professor-aluno, família-escola e entre os pares, experimentadas no exercício da profissão, mostrando como a importância atribuída pelas professoras a essas interações revelam a dimensão humana da docência e sua relação com a valorização docente.
\end{abstract}

Palavras chave: Condição docente; Interações humanas; Valorização docente.

\footnotetext{
1 Agradecemos à Coordenação de Aperfeiçoamento de Pessoal de Nível Superior (Capes) pelo apoio ao desenvolvimento das atividades da pesquisa.
} 
Abstract: Teachers' valorization has been increasingly highlighted by professionals and researchers of the educational area as one of the most important features that enable the construction of a more democratic society and enhance the quality of education. Based on this assumption, we present the outcomes of master's research aimed to investigate the teachers' valorization through the narratives of the professionals who teach the first levels of Brazilian elementary school within the municipal sector in Mariana, a town of Minas Gerais State, in conjunction with the theoretical references on the theme. We have concluded that the concept underlying the teachers' valorization is polyssemic and entails not only objective aspects such as formation, salary, working conditions and career plan but also subjective aspects, namely social recognition and professional achievement. Moreover, both aspects are embedded in the teachers' lives. The narratives of the teachers studied have revealed other aspects related to the working conditions which go beyond the goals accomplished by the municipality, such as the increase of the salary due to policies envolving the career plan. Similarly, we have dealt with little explored issues, such as the relationship between the teacher and the student, the family and the school and between the peers, all of these experienced throughout the develoment of the profession. In doing so, we show the importance of these interactions by the teachers and demonstrate the human dimension in the teaching task and its relationship with the teachers' valorization process.

Keywords: Human interactions; Teachers' condition; Teachers' valorization.

Resumen: La valorización docente ha sido, repetidamente enfatizada por los profesionales y estudiosos del área educacional como uno de los aspectos más importantes para la construcción de una sociedad más democrática y para la calidad de la educación. Basados en esa pre-suposición, presentamos resultados de una pesquisa de maestrazgo cuyo objetivo consistió en investigar la valoración docente, a partir de narraciones de profesoras de los años iniciales de la enseñanza fundamental de la red municipal de Mariana, Minas Gerais, en diálogo con referencias teóricas sobre la temática. Constatamos que el concepto de valoración docente es polisémico, envuelve aspectos objetivos (formación, remuneración, condiciones de trabajo y carrera) y subjetivos (reconocimiento social y la realización profesional) y como ambos aspectos se encuentran encajados en la vida de la profesora o del profesor. Basados en el relato de las profesoras pesquisadas, apuntamos otros aspectos contenidos en las condiciones de trabajo, para más allá de las conquistas alcanzadas en el municipio, como el aumento salarial proporcionado por el plan de carrera. De esa forma, abordamos asuntos poco trabajados en los estudios sobre la temática tales como: las relaciones profesor-alumno, familiaescuela y entre los pares, experimentados en el ejercicio de la profesión, mostrando como la importancia atribuida por las profesoras a esas interacciones revelan la dimensión valorización docente.

Palabras clave: Condición docente; Interacciones humanas; Valorización docente.

\section{Introdução}

A valorização docente tem sido, recorrentemente, enfatizada pelos profissionais e estudiosos da área educacional como um dos aspectos mais importantes para a construção de uma sociedade mais democrática e para a qualidade da educação. Apresentamos, nesse artigo, alguns dos resultados de uma pesquisa de mestrado em educação, na qual procuramos conhecer, a partir das narrativas, as percepções de cinco professoras dos anos iniciais do 
ensino fundamental que lecionam em escolas distintas do município de Mariana, Minas Gerais.

Além da pesquisa bibliográfica acerca da valorização docente, sentimos necessidade de ouvir os professores sobre o que pensam acerca dessa temática. A investigação, de natureza qualitativa, contou com a realização de entrevistas narrativas com as professoras participantes da pesquisa e com aplicação de questionário para levantamento do perfil sociocultural dessas entrevistadas. Utilizamos ainda, o caderno de campo que possibilitou o registro das impressões da pesquisadora ao longo da coleta de dados, tanto no que se refere à realização das entrevistas narrativas, propriamente ditas, como também no que diz respeito à estrutura física e características socioculturais das escolas e comunidades onde as professoras lecionam.

Conforme os pressupostos de Flick (2004), Silva e Pádua (2010), Muylaert et all (2014), Bolívar (2014), Souza (2006, 2014), entre outros, desenvolvemos as entrevistas narrativas, procurando estimular os relatos narrativos sobre a relação das professoras com a temática da valorização docente, tendo por base as suas trajetórias profissionais. A partir de então, as entrevistas foram transcritas conforme as orientações de Hartmann (2012) e os dados analisados segundo a interpretação hermenêutica, também denominada por Souza (2006) de análise compreensiva-interpretativa. A análise pautou-se na compreensão dos sentidos das narrativas docentes e sua relação com o contexto socio-histórico no qual as professoras atuam.

Dessa forma, as cinco professoras atuantes em cinco escolas municipais da cidade marianense apontaram-nos avanços e desafios no que se refere à promoção da valorização docente no município. Entre os avanços, destacaram a implantação do plano de carreira ${ }^{2}$ que elevou, substancialmente, a remuneração docente e regulamentou a carga horária de trabalho, destinando um terço da mesma para atividades de planejamento, avaliação e reuniões pedagógicas. Diante dessas conquistas, as docentes privilegiaram, em suas narrativas, os aspectos que ainda permanecem como entraves para a valorização docente, como a precariedade das condições de trabalho, especialmente, no que se refere à estrutura física e material das escolas. Do mesmo modo, suscitaram a importância das interações experenciadas no exercício da profissão, as quais contribuem para a percepção de valorização por parte das professoras e permanecem pouco contempladas pelos estudos da área.

${ }^{2}$ Lei Municipal no 139 de 29 de abril de 2014. 


\section{O conceito de valorização docente}

A expressão "valorização do magistério" "tem sido amplamente utilizada nos discursos das escolas, dos sindicatos, dos governos, da imprensa e dos partidos políticos e refere-se às dimensões objetivas e subjetivas da profissão, como destacou Leher (2010). As primeiras envolvem o regime de trabalho; piso salarial profissional; carreira docente; concurso público de provas e títulos; formação inicial e continuada; tempo remunerado para estudos, planejamento e avaliação, assegurado no contrato de trabalho, e condições de trabalho. Por sua vez, as condições subjetivas compreendem o reconhecimento social da profissão e a realização profissional. Conforme a definição apresentada pelo autor, a compreensão da valorização docente exige a análise do contexto social e educacional onde o professor atua, pois, ainda que pertencente a uma mesma rede ou nível de ensino, as escolas e suas comunidades comportam particularidades que incidem sobre o exercício da profissão. Sindicatos e organizações representativas do movimento docente tiveram papel importante na elaboração das políticas de valorização docente no Brasil (LEHER, 2010), processo favorecido por um debate que mobilizou diferentes segmentos da sociedade ao longo dos últimos quarenta anos. Nesse período, “os sentidos sobre a valorização do professor foram se definindo, ampliando e se fixando no embate das propostas formuladas por instâncias da sociedade civil e da sociedade política” (WEBER, 2015, p. 496).

Como parte desse processo, a valorização docente foi incorporada pela Constituição Federal de 1988 e por todo um conjunto de políticas educacionais que a consubstanciaram, tais como a Lei de Diretrizes e Bases da Educação Brasileira promulgada em 1996, o Fundo de Manutenção e Desenvolvimento do Ensino Fundamental e de Valorização do Magistério (FUNDEF) implantando em 1996, o qual passou a compor o Fundo de Manutenção e Desenvolvimento da Educação Básica e de Valorização dos Profissionais da Educação (FUNDEB) em 2007, as Diretrizes para os Planos de Carreira e Remuneração em 1997, o Piso Salarial Nacional em 2008, o Plano Nacional de Educação (2001-2011) e o atual Plano Nacional de Educação (2014-2024).

Essas determinações, salvo suas especificidades, ressaltaram a importância da formação inicial e continuada, da remuneração e das condições de trabalho e carreira para a promoção da valorização docente. Tais aspectos objetivos da profissão têm orientado, de

\footnotetext{
3 Leher (2010) analisa o conceito "valorização do magistério" e não "valorização docente". Mesmo assim, optamos por apresentá-lo aqui considerando sua relação com o tema da pesquisa.
} 
maneira dominante, os estudos sobre a temática da valorização dos professores no país (CIRILO, 2012). Entretanto, ao realizarmos as entrevistas narrativas, constatamos que, na perspectiva das professoras pesquisadas, a valorização docente abarca também algumas questões de natureza subjetiva, confirmando assim a assertiva de Leher (2010), citada anteriormente.

\section{A valorização docente nas narrativas das professoras pesquisadas}

Embora as questões referentes à melhoria da formação, remuneração, condições de trabalho e carreira sejam essenciais para a valorização docente, as narrativas das professoras pesquisadas evidenciaram que a questão ultrapassa os aspectos objetivos. Ao longo do processo de coleta e análise dos dados da pesquisa, verificamos a importância que as professoras atribuem aos aspectos subjetivos.

Sabemos que a subjetividade docente está relacionada ao contexto social e histórico no qual o professor atua e refere-se aos aspectos do pensamento, das emoções, da vontade e das práticas do professor, como sugeriu Mancebo (2010). Sentir-se valorizado ou não é algo subjetivo, depende da percepção de cada professor que, individualmente, constrói suas relações com a profissão, com os alunos, as famílias e os pares ao longo de sua trajetória profissional. Contudo, não podemos perder de vista que a subjetividade é influenciada por aspectos externos ao indivíduo, ou seja, é construída mediante condições concretas de exercício da profissão. Trata-se de "um conjunto de fenômenos relacionados e em processo, produzidos subjetivamente na relação com a objetividade, que é material e social" (MANCEBO, 2010, s/página). Portanto, conforme destaca a autora, os aspectos objetivos e subjetivos articulam-se para conformar a subjetividade docente. Nesse contexto, destaca-se a importância das condições de trabalho, as quais influenciam a percepção do professor em relação à profissão e, consequentemente, em relação à valorização docente. Dentre as questões que compreendem as condições de trabalho docente, verifica-se que a dimensão econômica é a mais enfatizada pela mídia e pelos discursos políticos e está diretamente relacionada à imagem social da docência. (ARROYO, 2011).

No município de Mariana, a elevação da remuneração dos professores dos anos iniciais foi promovida pelo plano de carreira da categoria, implantado em 2014. A valorização salarial docente é destacada na meta 17 do PNE (Plano Nacional de Educação) e do PME (Plano Municipal de Educação). Ambas as regulamentações definem, por meio da referida 
meta, que o rendimento médio dos professores da educação básica deve respeitar o cumprimento do PSPN (Piso Salarial Profissional Nacional). No município pesquisado, o valor do piso salarial tem se mantido superior ao valor do piso nacional desde o ano de 2013, conforme demonstra o quadro a seguir:

\section{Quadro 1 - Comparativo do valor do piso de Mariana/MG com o piso nacional}

\begin{tabular}{|c|c|c|}
\hline Ano de vigência & Piso de Mariana & Piso nacional \\
\hline 2009 & $\mathrm{R} \$ 846,55$ & $\mathrm{RS} 950,00$ \\
\hline 2010 & $\mathrm{R} \$ 897,34$ & $\mathrm{R} \$ 1.024,67$ \\
\hline 2011 & $\mathrm{R} \$ 1.327,69$ & $\mathrm{R} \$ 1.187,14$ \\
\hline 2012 & $\mathrm{R} \$ 1.407,35$ & $\mathrm{R} \$ 1.451,00$ \\
\hline 2013 & $\mathrm{R} \$ 1.717,00$ & $\mathrm{R} \$ 1.467,00$ \\
\hline 2014 & $\mathrm{R} \$ 2.750,00$ & $\mathrm{R} \$ 1.697,39$ \\
\hline 2015 & $\mathrm{R} \$ 2.942,50$ & $\mathrm{R} \$ 1.917,78$ \\
\hline
\end{tabular}

Fonte: Dados do Plano Municipal de Educação da Prefeitura Municipal de Mariana/Recursos Humanos

Entretanto, ainda que a oferta de uma remuneração digna seja essencial para a valorização docente, ela por si não é suficiente, uma vez que as condições de trabalho extrapolam a questão salarial. A noção de condições de trabalho abarca todo um conjunto de recursos que viabilizam a realização da atividade, o qual pressupõe a disponibilidade de instalações físicas, os materiais, equipamentos e outros tipos de apoio necessários relacionados à natureza do trabalho desenvolvido. Diz respeito também às relações de emprego, referentes às formas de contratação, carreira, estabilidade e remuneração (OLIVEIRA; ASSUNÇÃO, 2010, s/página). Essa assertiva é corroborada pelas professoras entrevistadas:

Eu acho que você vê que não é tão valorizada pelo governo por [ele] não te dar suporte pra você tá trabalhando. Não adianta você ser valorizado só com essas questões de salário! Eu acho que tem que ter toda uma estrutura, né? Material didático e a estrutura física do ambiente também (Professora Edinalva $\left.{ }^{4}\right)$.

$\mathrm{Eu}$ espero que mais cursos possam acontecer pra gente, né? E que o professor seja muito mais valorizado. Financeiramente, se você olhar em Minas Gerais, o salário do professor [no município] é um dos melhores

\footnotetext{
${ }^{4}$ De acordo com o projeto aprovado pelo Comitê de Ética em Pesquisa da Universidade Federal de Ouro Preto, utilizamos de pseudônimos para preservar a identidade das professoras.
} 
salários de Minas Gerais. Claro que a gente necessita mais? Necessitamos sim. Temos que ser valorizados sim! Mas, não só financeiramente, mas também a nossa valorização humana ${ }^{5}$. Valorizar o professor, o ser humano em si. Dar a ele condições de desenvolver um bom trabalho, né? Não só financeiramente, mas também dentro de sala de aula, recursos materiais que a gente necessita também (Professora Raimunda).

Dessa forma, as narrativas das professoras evidenciam a complexidade e a importância das condições de trabalho do professor, especialmente, no que se refere à estrutura física e material, mas deixam transparecer que outros aspectos da condição docente também são importantes. Isso nos remete à teorização de Arroyo (2011, p. 64):

O grave das condições materiais e de trabalho das escolas não é apenas que é difícil ensinar sem condições, sem material e sem salários, o grave é que nessas condições nos desumanizamos todos. Não apenas torna-se difícil ensinar e aprender os conteúdos, torna-se impossível ensinar-aprender a ser gente. As condições que impedem ou permitem essas aprendizagens são materiais, mas são também de estrutura, de organização e de clima humano ou de relações sociais, humanas, culturais.

Nessa direção, Freire (1997, p. 50) ressalta que o espaço escolar produz um discurso que também contribui na formação do aluno:

É incrível que não imaginemos a significação do 'discurso' formador que faz uma escola respeitada em seu espaço. A eloquência do discurso 'pronunciado' na e pela limpeza do chão, na boniteza das salas, na higiene dos sanitários, nas flores que adornam. Há uma pedagogicidade indiscutível na materialidade do espaço.

Como podemos perceber, aspectos objetivos e subjetivos da profissão docente encontram-se inter-relacionados. As condições de exercício de profissão interferem naquilo que é mais caro para o docente: as relações humanas, como apontou Arroyo (2011). Também a narrativa da professora Cristina nos mostra essa confluência de dimensões objetivas e subjetivas da profissão, lembrando a importância de considerar esse aspecto na discussão da valorização docente.

No meu ponto de vista, existem dois fatores que percebo que valorizam a gente enquanto profissional: seriam os internos e os fatores externos. [...] Os fatores internos eles são intrínsecos a mim mesmo, pertencem a mim e são eles que me motivam. [...] Ver e ter a certeza de que um aluno está aprendendo, não tem preço. Não tem. Com relação à questão de valorização, o que me motiva é buscar conhecimento mesmo, saber que eu tô contribuindo. Quanto aos fatores externos, que são os cursos, as palestras e a

\footnotetext{
${ }^{5}$ Conforme sugestão de Hartmann (2012), as palavras ou expressões que aparecem em negrito no texto foram pronunciadas com ênfase pelas próprias entrevistadas.
} 
realização material, que você até tem sim, a gente não pode deixar de falar que tem, mas ainda assim, não é, não se tem uma valorização financeira tão elevada. Então, pra mim, nem é a principal. [...] Me sinto também valorizada quando posso sugerir algum projeto, alguma situação que vai tá mais contextualizada e os meus colegas de trabalho conseguem compreender e aceitar... (Professora Cristina).

Os aspectos objetivos ou externos, conforme denominado pela professora, são de responsabilidade do poder público e compreendem as condições de trabalho do professor, bem como a formação e a remuneração. Ao mesmo tempo, ressalta-se em sua narrativa a satisfação das relações positivas com os alunos e com os colegas de trabalho. Esses aspectos, remetem-nos à centralidade das interações humanas na docência, como apontaram Tardif e Lessard (2005), evidenciada pela importância que os professores atribuem a relação com o outro. Dentre o conjunto de interações que o professor estabelece em sua prática, destaca-se a relação com os alunos, por conta de seu caráter emocional e afetivo (TARDIF; LESSARD, 2005; TARDIF, 2012):

Eu me sinto valorizada é pelo retorno das crianças, pelo carinho [que recebo delas] (Professora Edinalva).

Eu não vejo eles como meus alunos. Eu vejo eles como meus meninos! (Professora Raimunda)

Nesse sentido, as relações com os alunos compõem o "nó central" (TARDIF; LESSARD, 2005) da profissão docente e comportam parte significativa das alegrias e tensões da docência. Contudo, não se trata de uma relação meramente afetiva, uma vez que o aprendizado dos alunos desafia e motiva os professores:

A gente vê uma valorização, independente de todas as dificuldades, na hora que você vê um aluno lendo, um aluno fazendo uma atividade que não tava conseguindo, mas que você viu: Nossa! Agora sim. É aí que eu me sinto valorizada (Professora Francisca).

A narrativa acima evidencia o compromisso para com o desenvolvimento dos alunos, um compromisso que, segundo Teixeira (2007) é político, uma vez que manifesta o cuidado docente para com a formação do aluno. No entendimento de Gadotti (2011, p. 65), "há muitos professores e professoras que se sentem infelizes na escola e principalmente na sala de aula. Falta interesse, falta disciplina, faltam objetivos claros, enfim, falta sentido para o que ensinam”. Mas esse não é o caso da professora Francisca, como podemos ver a seguir.

[...] Tem menino que briga, sai da carteira, vai lá incomoda o outro, bate no outro. Aí, você tem que parar sua aula pra chamar a atenção. É que some 
uma borracha, some não sei o quê. Não sei quem pegou o meu lápis, não sei quem pegou minha bolsinha e escondeu. Aí, você perde muito tempo na aula, mas quando você vê uma evolução em alguma coisa nos seus alunos, aí você sente valorizada. Aí, você fala assim: pronto. Agora, posso respirar. Tô vendo que o meu trabalho, mesmo com toda dificuldade, tá surtindo efeito. Alguma coisa eu tô vendo que eu tô plantando ali e eu tô conseguindo alcançar alguma coisa com ele. O meu objetivo tá sendo feito. Aí sim que eu acho que a gente é valorizado (Professora Francisca).

A falta de interesse pela escola e a indisciplina dos alunos podem ter sua origem na ausência de sentido do aprendizado, daí a importância do/a professor/a buscar junto com os alunos esse sentido do aprender e do ensinar, como ressaltou Gadotti (2011). Às vezes, a disciplina se manifesta por meio de condutas menos problemáticas como, por exemplo, nas conversas paralelas e na ausência de participação, conforme apontam Tardif e Lessard (2005). Contudo, em contextos sociais mais vulneráveis, a indisciplina escolar esbarra na violência urbana:

Os alunos eles são assim... [silêncio] Eles tão naquela fase que de rebeldia tão grande porque é aluno [sussurra com medo de ser ouvida por pessoas que estão na rua e completa: que usa droga dentro da escola]. Leva droga pra quadra, entendeu? [fala baixo] E assim, não respeita os professores. Manda tomar no [...], fala coisas horrorosas com os professores. E assim, eram alunos que eram nossos. Alunos que a gente conviveu desde pequeno. E foi pro $6^{\circ}$ ao $9^{\circ}$ ano e se tornaram rebelde de uma tal forma... E isso a gente fica chateado, porque são colegas nossos de escola, né? E a gente vê a frustração deles. Pro cê ter uma ideia, neste ano, acho que todos.... ou se não foi todos, quase todos, pediram transferência. Cê vê a dificuldade que está sendo, entendeu? Tá sendo trabalhado, a Prefeitura, a equipe da nova gestão tá ajudando? Tá. Tá participando? Tá. Mas, só que tem que estar mais junto deles, porque eles não tão passando.... eles tão tendo muita dificuldade mesmo. Como que você vai debater com um jovem que cá fora ele.. [gesticula uma arma de fogo], né? Como que cê vai debater com um jovem que ele não tá nem aí? Se amanhã, ele te matar, pronto, né? Então, tem esses problemas muito graves aqui na escola, né? Na comunidade em si, não na escola. A comunidade. E os professores eles ficam frustrados, porque vai dar uma aula, não consegue dar uma aula, né? Tem dificuldade. Claro que tem $\mathrm{N}$ coisas que acontece, que poderia ser modificada até por eles também. Mas, só, que eles se sentem mesmo coagidos, eles se sentem assim, acho que decepcionados com as coisas que acontece... E nada tá sendo resolvido, porque... [gesticula demonstrando que não tem jeito]. (Professora Raimunda)

Percebe-se assim, que a questão da indisciplina associada à violência urbana interfere, diretamente, nas interações entre professores e alunos e, consequentemente, em sua percepção sobre a docência. A violência escolar constitui-se como um dos grandes desafios no exercício da profissão, atualmente. Esse fenômeno abarca condutas bastante diversas, tais como: agressões físicas, ameaças graves, pequenas brigas, assédio, palavras racistas, 
indisciplina escolar, indiferença ostentatória para com os assuntos da escola - que incorrem sobre a escola, a família e a sociedade (CHARLOT, 2014). Essas questões geram um sentimento de impotência por parte dos professores (TARDIF e LESSARD, 2005) por conta das poucas possibilidades de intervenção e porque incidem sobre um dos aspectos centrais da docência: a relação professor-aluno.

As interações desenvolvidas em sala de aula contribuem para a formação da identidade profissional dos professores, uma vez que o docente reconhece a importância do seu trabalho no desenvolvimento dos alunos. Constituem, ainda, o principal fator de motivação para os docentes e demonstram um engajamento afetivo dos professores com os alunos e com a sua formação, conforme destacado por Tardif e Lessard (2005, p. 70):

Um professor não trabalha sobre os alunos, mas com e para os alunos, e precisa preocupar-se com eles. Ademais, para um bom número de professores, a opção por essa profissão é resultado de uma vontade de ajudar os jovens, as crianças.

Esse aspecto também é destacado por Arroyo (2011, p. 231): “As práticas cotidianas da escola giram em torno dos educandos, da formação de sua mente, dos domínios das competências, de sua formação como humanos". Essas práticas ocorrem em todo o estabelecimento escolar, mas é, especialmente, a sala de aula que se constitui como espaço privilegiado de interações com os alunos.

Ao entrar em sala de aula, o professor penetra em um ambiente de trabalho constituído de interações humanas. As interações com os alunos não apresentam, portanto, um aspecto secundário ou periférico do trabalho dos professores: elas constituem o núcleo e, por essa razão, determinam ao nosso ver, a própria natureza dos procedimentos e, portanto, da pedagogia. (TARDIF, 2012, p. 118).

Nesse sentido, as demais interações profissionais desenvolvidas pelos professores, seja entre a equipe escolar ou com as famílias, também se justificam pelo desenvolvimento dos alunos. Segundo Tardif e Lessard (2005, p. 141), “ensinar é trabalhar com seres humanos, sobre seres humanos, para seres humanos". O conjunto dessas interações compõe um dos fatores de maior satisfação e, ao mesmo tempo, de desafio para os professores, por exemplo, no que se refere à relação família e escola:

Ah, se a família participasse, eu me sentiria mais valorizada tanto que eu acho que o trabalho seria melhor, porque a gente precisa dessa parceria família e escola e como tem umas mães que não apoiam seus filhos e não, assim, acompanham a sua vida escolar, então, eu acho que atrapalha um pouco e 
impede de algumas coisas que a gente poderia tá conseguindo mais (Professora Francisca).

O sucesso do aluno é também o sucesso do professor e a participação da família na vida escolar das crianças é considerada pelas docentes um componente importante nesse contexto. "Quando os pais, mães, ou outros responsáveis, acompanham a vida escolar de seus filhos, aumentam as chances da criança aprender" (GADOTTI, 2007, p.12) e, consequentemente, de êxito do trabalho docente. Entretanto, quando não percebem o envolvimento da família, os docentes têm a impressão de exercerem um trabalho solitário e desvalorizado:

De 23 alunos, na reunião que a gente fez pra poder pedir o reforço [...] para os meninos que precisam aprender a ler e eu taria trabalhando alfabetização com eles, pergunta se veio algum pai. Vieram uns 4 pais. Vieram uns 4 pais só! Então assim, você fica sem ter o que fazer. Eu acho que isso aí, a gente está sendo desvalorizada, porque se a família não quer ajudar, a família não tá apoiando o professor, nem nada, então assim, você está sendo desvalorizado. (Professora Ângela).

Nos dias atuais, percebe-se que os espaços de atuação entre a família e a escola estão cada vez mais imbrincados (NOGUEIRA, 2005; BOLÍVAR, 2006) muito em função das transformações ocorridas na sociedade, na família e na escola (TEDESCO e FANFANI, 2004). Essas transformações têm acarretado uma dilatação das atribuições da escola - não sem profundas tensões - a qual tem assumido a formação integral da criança (formação moral, cívica e socialização primária) e o desenvolvimento cognitivo e cultural em meio à complexidade e instabilidade de um conjunto de saberes (BOLÍVAR, 2006). Percebe-se certo "lamento nostálgico em relação a uma escola perdida que não voltará mais" (BURGOS, 2014, p. 64), aspecto também destacado na narrativa da professora Ângela:

Hoje a educação é como se fosse um depósito! A escola é como se fosse um depósito de menino. E antes [...] eu acho que a gente tinha mais valor pros pais, pra família do que nos dias de hoje. Os pais procuravam mais.... Reuniões de pais eram mais cheias, tinha mais participação... A família contribuía com tudo que eu pedisse... Eu sentia prazer em ir trabalhar, sabe? Tudo que você propunha fazer a família tava disposta a participar [...] Teve até uma reunião de pais que eu falei isso. A escola sozinha não faz nada pelo aluno, né? É, uma participação da família que tem que ter. E nem a família faz sozinha. Então, eu falava que o sucesso que eu tava tendo com os meninos é porque as famílias participavam muito, muito mesmo. (Professora Ângela).

No entendimento de Thin (2006), pais pouco escolarizados não se envolveriam, efetivamente, na escolarização das crianças por receio de prejudicá-las. Para Burgos (2014), a 
suposta falta de interesse seria, na verdade, confiança das famílias populares na escola e respeito ao trabalho dos professores. Segundo o autor, as famílias populares valorizam a escola e o trabalho docente. No entanto, suas estratégias em relação à escolarização dos filhos não são percebidas pelos professores, porque se desenvolvem no ambiente doméstico. Essas estratégias constituem-se como um tipo de "envolvimento invisível”, imperceptível aos olhos dos professores e condicionado pelo contexto sociocultural no qual os alunos e suas famílias se inserem.

Contextos socioculturais menos favorecidos impõem problemas diversos aos alunos e suas famílias, como a ausência de um dos pais, a insuficiência de recursos materiais, sociais e simbólicos. Essas adversidades são, frequentemente, ignoradas pelas exigências da escola, as quais se baseiam em um modelo de família do tipo nuclear ideal, como apontou AcuñaCollado (2016).

Além disso, a escola teve suas responsabilidades ampliadas, especialmente, em tempos de ofensiva neoliberal e consequente diminuição da participação do Estado na oferta de serviços sociais. Todas essas transformações, ocorridas nas últimas décadas, vem exigindo dos professores uma nova profissionalidade docente (BOLÍVAR, 2006; TEDESCO E FANFANI, 2004). Nesse sentido, não só a escola e os docentes precisam repensar o seu papel nesse novo contexto social e histórico, mas também se exige do poder público políticas mais efetivas de inclusão social.

A escola não pode mudar tudo e nem pode mudar a si mesma sozinha. Ela está intimamente ligada à sociedade que a mantém. Ela é, ao mesmo tempo, fator e produto da sociedade. Como instituição social, ela depende da sociedade e, para se transformar, depende também da relação que mantém com outras escolas, com as famílias, aprendendo em rede [grifos do autor] com elas, estabelecendo alianças com a sociedade, com a população. (GADOTTI, 2007, p.12).

Uma necessidade imperiosa de se preparar para as relações de convivência em sala de aula e resolução de conflitos emerge dessas novas exigências sobre o trabalho docente, como apontou Acuña-Collado (2016). Destaca-se aqui a necessidade de espaços para a reflexão sobre a relação entre a família e a escola, a construção de novas estratégias de participação e a promoção da capacidade de diálogo com as famílias, que podem ser ocupados com a formação inicial e continuada, assim como de projetos de trabalho desenvolvidos pela equipe escolar. A esse respeito, Bolívar (2006) menciona também o papel da equipe diretiva na adoção de estratégias de estímulo à participação familiar, na construção de relações de 
confiança entre os professores e as famílias e na capacitação dos professores para estabelecerem relações positivas e contínuas com as famílias.

Outra dimensão das interações humanas na escola, destacada nas narrativas das professoras entrevistadas, foi o trabalho em equipe. As dificuldades enfrentadas pelos docentes em território de alta vulnerabilidade social motivam a união entre os colegas da escola, como mostra a professora Raimunda:

Meu pai brinca assim: que eu sou presa... que meu umbigo tá enterrado nessa escola [risos] devido ao fato de os professores, a equipe de trabalho é muito unida. E isso contribui muito pra que a gente permaneça no lugar, né? E, e, e a maioria que aqui estão, é dez, quinze, vinte... Toda a vida trabalhou aqui e continua, não têm vontade de sair daqui, né? Principalmente, nós de $1^{\mathrm{a}}$ a $4^{\mathrm{a}}$, por causa da questão da equipe mesmo. Por causa da questão de estarmos sempre juntas, contribuindo, né? Pra tentar, pelo menos, sanar um pouco das dificuldades que essa comunidade enfrenta (Professora Raimunda).

O trabalho em equipe, segundo a professora, favorece o vínculo entre as docentes e a comunidade e pode atenuar algumas dificuldades vivenciadas pelos alunos, o que nos remete à importância da socialização entre os pares. Além disso, favorece o desenvolvimento do trabalho docente e a valorização do professor:

Essa valorização entre a gente, a pedagoga, é a questão assim: um tenta ajudar o outro, né? Eu tenho uma atividade que não é pra mim, mas serve pra outra [professora]. Então, a gente sempre tenta um ajudar o outro. [...] A gente preocupa muito com isso, com essa valorização mesmo da gente, da equipe mesmo (Professora Raimunda).

A diversificação das demandas para a educação, assim como o novo perfil dos alunos que chegam hoje às escolas, estão a exigir uma nova cultura do profissionalismo coletivo, como nos alertaram Tedesco e Fanfani (2004). Muitas vezes, as trocas entre os colegas da equipe escolar dizem respeito aos conhecimentos práticos utilizados pelos professores para atingir seus objetivos de trabalho e resolver possíveis problemas, como ressaltou Arroyo (2011).

O que me ajuda também no meu trabalho é porque eu tenho uma colega que... como aqui a gente tem dois $3^{\circ}$ s anos, então a gente troca muita experiência. Então, ela me passa algumas atividades, eu passo atividades pra ela. Então, isso que vai ajudando e a gente faz a divisão. Como são dois $3^{\circ} \mathrm{s}$ anos, uma semana uma faz uma atividade, a outra faz. Então, essa troca que tenho com a minha colega é bem enriquecedora (Professora Francisca).

Essa relação entre os pares para troca de 'conhecimentos utilitários' (ARROYO, 2011, p. 172) foi reconhecida por uma das entrevistadas, porém, vimos que também a 
extrapola. Mais do que o desenvolvimento de ações pontuais com objetivos específicos, as interações entre os pares constituem-se uma importante possibilidade de formação e autoformação docente, muitas vezes, despercebida pelos gestores educacionais e pelos próprios professores:

Temos que ampliar o olhar sobre os processos formadores dos educadoresdocentes. Os que deixam marcas não são os pontuais nas horas dos cursos dados por centros de formação. A formação acontece na totalidade das práticas e, sobretudo, no movimento educativo que as propostas legitimam e incentivam. Os tempos pontuais de requalificação, de estudo e as ações dos centros encontram sentido se fizerem parte dessa dinâmica total, se estiverem sintonizados com ela, se extraírem dela mais significados. Provocar, incentivar uma dinâmica inovadora no coletivo de uma escola ou de uma rede é a melhor estratégia de requalificação dos docentes. (ARROYO, 2011, p. 136).

Nessa direção, a troca de experiência entre os pares, embasada na reflexão crítica sobre a prática, seja por meio de relatos de experiências, oficinas ou de grupos de trabalho, faz parte do processo de formação permanente, sendo importante para o desenvolvimento de um paradigma colaborativo entre os docentes. Dessa forma, é por meio da cooperação e do companheirismo que os docentes irão conseguir superar as atuais condições do magistério (GADOTTI, 2011) e romper com a cultura tradicional docente, baseada na autonomia individual e no controle burocrático (TEDESCO; FANFANI, 2004).

Portanto, a superação da formação individualista do professor em direção à cultura do profissionalismo coletivo e do trabalho em equipe exige pensar a instituição como conjunto e não apenas na sala de aula como unidade de trabalho. É por meio da reflexão coletiva e de projetos comuns de trabalho que os docentes poderão construir um conhecimento profissional coletivo sobre a educação e o contexto social, tornando possível a emergência de um novo paradigma educacional (IMBERNÓN, 2011).

A noção de qualidade precisa mudar profundamente: a competência profissional deve ser medida muito mais pela capacidade do docente estabelecer relações com seus alunos e seus pares, pelo exercício da liderança profissional e pela atuação comunitária, do que pela sua capacidade de "passar conteúdos". (GADOTTI, 2011, p. 36).

Esse novo conceito de competência profissional nos revela outra faceta da dimensão humana da docência ou a "humana docência", conforme se refere Arroyo (2011) à profissão docente. Mais do que produzir conhecimento e estimular o aprendizado, a docência configurase como um trabalho eminentemente interativo (TARDIF, 2012; LESSARD; TARDIF; 2011). A construção coletiva de uma reflexão sobre o lugar da educação e sobre o lugar da profissão 
docente em meio ao atual contexto social é essencial para a oferta de uma educação de qualidade para todos, bem como para a valorização docente.

\section{Considerações finais}

Podemos depreender dessas reflexões, a polissemia do conceito de valorização docente, o qual abarca dimensões objetivas e subjetivas (LEHER, 2010). As primeiras correspondem à formação, remuneração, condições de trabalho e carreira. Dentre essas dimensões, a questão econômica é a que tem sido mais enfatizada pela mídia e pelos discursos políticos (ARROYO, 2011). Ainda que a oferta de uma remuneração digna seja essencial, ela por si só, não garante a valorização docente em termos objetivos, uma vez que as condições de trabalho dos professores envolvem também a estrutura física e material das instituições, o processo de formação, entre muitos outros aspectos.

Destacou-se, ainda, a importância das interações humanas vivenciadas pelos professores no exercício da profissão, as quais integram a dimensão subjetiva da docência. A começar pela relação professor-aluno, que envolta em meio à afetividade docente, é fonte de motivação e de desafio, que interfere na construção coletiva de sentido aos conhecimentos escolares, tanto para o professor quanto para o aluno.

Na narrativa dos docentes entrevistados, a participação da família na vida escolar da criança também se apresenta como fator relevante de valorização docente, na medida em que é vista como capaz de contribuir para o desempenho do aluno e para que o professor se sinta realizado. Tais questões nos remetem à necessidade de considerar - na formação e na atuação docentes - a relação família-escola como recurso importante na promoção da aprendizagem dos alunos e também de valorização docente. Nessa perspectiva, quando a família demonstra seu envolvimento com a escolarização das crianças, esta aproximação se mostra um aliado importante para o sucesso da aprendizagem dos alunos.

No entanto, a relação família e escola não se restringe ao espaço escolar, uma vez que sofre as influências do contexto sociocultural onde alunos e professores se inserem e que, frequentemente, é acometido pela desigualdade social e pelos problemas dela advindos. Essa realidade estabelece novas exigências aos professores (ACUÑA-COLLADO, 2016) e sugere a necessidade de reflexão e diálogo sobre a proximidade entre o mundo da escola e o mundo do aluno (BURGOS, 2014). Além disso, impõe ao poder público a elaboração de políticas mais 
efetivas de inclusão social. Em algumas situações, os desafios relacionados às questões sociais, extrapolam a competência dos professores, bem como a atuação da escola.

Em meio aos desafios da profissão, o trabalho em equipe e a socialização entre os pares também se destacou como um fator que promove o vínculo com a escola e a comunidade e, ao mesmo tempo, auxilia os docentes em sua prática diária. Mais do que a troca de informações pontuais e atividades do cotidiano, o trabalho colaborativo pode favorecer a reflexão sobre a prática docente e a educação como um todo.

\section{REFERENCIAS}

ACUÑA-COLLADO, Violeta. Familia y escuela: crisis de participación en contextos de vulnerabilidade. Revista Brasileira de Estudos Pedagógicos. Brasília, v. 97, n. 246, p. 255 272, maio/ago. 2016.

ARROYO, Miguel. Ofício de mestre: imagens e autoimagens. Petrópolis: Vozes, 2011.

BOLÍVAR, Antonio. Familia y escuela: dos mundos llamados a trabajar en común. Revista de Educación, v.339, n.2006, p.119-146, 2006.

BOLÍVAR, Antonio. Las historias de vida del professorado: voces y contextos. Revista Mexicana de Investigacion Educativa, núm. 62 (julio-septiembre),p.711-734, 2014.

BRASIL. Constituição (1988). Constituição da República Federativa do Brasil de 1988. Senado Federal. Subsecretaria de Edições Técnicas, 1988. Disponível em <http://www.planalto.gov.br/ccivil_03/constituicao/constituicaocompilado.htm>.Acesso em 20 jan. 2017.

BRASIL. Lei no 9.394, de 20 de dezembro 1996. Estabelece as diretrizes e bases da educação nacional. Diário Oficial da União, Brasília, 20 de dezembro de 1996. Disponível em: <http://www.planalto.gov.br/ccivil_03/leis/L9394.htm>_Acesso em: 15 jan. 2017.

BRASIL. Lei n ${ }^{\circ} 9424$ de 24 de dezembro de 1996. Dispõe sobre o Fundo de Manutenção e Desenvolvimento do Ensino Fundamental e de Valorização do Magistério, na forma prevista no art. $60, \S 7^{\circ}$, do Ato das Disposições Constitucionais Transitórias, e dá outras providências. Diário Oficial da União, Brasília, 24/12/1996. Disponível em <http://www.planalto.gov.br/ccivil_03/leis/L9424.htm>. Acesso em: 20 jan. 2017.

BRASIL. Lei no 11.494, de 20 de junho de 2007. Regulamenta o Fundo de Manutenção e Desenvolvimento da Educação Básica e de Valorização dos Profissionais da Educação FUNDEB, de que trata o art. 60 do Ato das Disposições Constitucionais Transitórias; altera a Lei no 10.195, de 14 de fevereiro de 2001; revoga dispositivos das Leis nos 9.424, de 24 de dezembro de 1996, 10.880, de 9 de junho de 2004, e 10.845, de 5 de março de 2004; e dá outras providências. Diário Oficial da União, Brasília, 20 de junho de 2007. Disponível em: 
<http://www.planalto.gov.br/ccivil_03/_ato2007-2010/2007/Lei/L11494.htm>. Acesso em: 15 fev. 2017.

BRASIL. Lei no 10.172, de 9 de janeiro de 2001. Aprova o Plano Nacional de Educação e dá outras providências. Diário Oficial da União, Brasília, 09 de janeiro de 2001. Disponível em: <http://www.planalto.gov.br/ccivil_03/leis/leis_2001/110172.htm>. Acesso em: 15 jan. 2017.

BRASIL. Lei no 11.738/2008. Regulamenta a alínea "e" do inciso III do caput do art. 60 do Ato das Disposições Constitucionais Transitórias, para instituir o piso salarial profissional nacional para os profissionais do magistério público da educação básica. Diário Oficial da União, Brasília, 16 de julho de 2008. Disponível em: <http://www.planalto.gov.br/ccivil_03/_ato2007-2010/2008/lei/111738.htm>. Acesso em: 21 fev. 2017.

BRASIL. Lei 13.005, de 25 de junho de 2014. Aprova o Plano Nacional de Educação - PNE e dá outras providências. Diário Oficial da União, Brasília, 25/06 de 2014. Disponível em: <http://www.planalto.gov.br/ccivil_03/_ato2011-2014/2014/lei/113005.htm>. Acesso em: 20 fev. 2017.

BURGOS, Marcelo Baumann (Coord.). A escola e o mundo do aluno: estudos sobre a construção social do aluno e o papel institucional da escola. Rio de Janeiro: Garamont, 2014.

CHARLOT, Bernard. Da relação com o saber às práticas educativas. São Paulo: Cortez, 2014.

CIRILO, Pauliane Romano. As políticas de valorização docente no Estado de Minas Gerais. 2012. 154 f. Dissertação (Mestrado em Educação). Faculdade de Educação, Universidade Federal de Minas Gerais, 2012.

FLICK, Uwe. As narrativas como dados. In: FLICK, Uwe. Uma introdução à pesquisa qualitativa. $2^{\text {a }}$ ed. Porto Alegre, Bookman, 2004.

FREIRE, Paulo. Pedagogia da autonomia. São Paulo: Paz e Terra, 1997.

GADOTTI, Moacir. A boniteza de um sonho. São Paulo: Editora e Livraria Instituto Paulo Freire, 2011.

GADOTTI, Moacir. A escola e o professor: Paulo Freire e a paixão de ensinar. São Paulo: Pubblisher Brasil, 2007.

GATTI, Bernardete (Org.). O trabalho docente: avaliação, valorização, controvérsias. Campinas, SP: Autores Associados: São Paulo: Fundação Carlos Chagas, 2013.

HARTMANN, Luciana. Tomazito, eu e as narrativas: "Por que estoy hablando de mi vida". In: GONÇALVES, Marco Antônio; MARQUES, Roberto; CARDOSO, Vânia Z. (Orgs.). Etnobiografia: subjetivação e etnografia. Rio de Janeiro: 7 Letras, 2012.

IMBERNÓN, Francisco. Formação docente e profissional: formar-se para a mudança e a incerteza. São Paulo: Cortez, 2011. 
LEHER, Roberto. Valorização do magistério. In: OLIVEIRA, Dalila Andrade; DUARTE, Adriana Maria Cancella e VIEIRA, Lívia Fraga. DICIONÁRIO: trabalho, profissão e condição docente. Belo Horizonte: UFMG/Faculdade de Educação, 2010 CDROM.

MUYLAERT, Camila Junqueira et al. Entrevistas narrativas: um importante recurso em pesquisa qualitativa. Revista da Escola de Enfermagem da USP, v.48, n.2, 2014.

MANCEBO, Deise. Subjetividade docente. In: OLIVEIRA, Dalila Andrade; DUARTE, Adriana Maria Cancella e VIEIRA, Lívia Fraga. DICIONÁRIO: trabalho, profissão e condição docente. Belo Horizonte: UFMG/Faculdade de Educação, 2010 CDROM.

MARIANA. Prefeitura Municipal. Lei no 3.042 de 23 de dezembro de 2015. Aprova o Plano Municipal de Educação e dá outras providências. O Monumento - Diário oficial. Disponível em:<http://www.mariana.mg.gov.br> Acesso em: 20 mai. 2017.

MARIANA. Prefeitura Municipal. Lei no 139 de 29 de abril de 2014. Dispõe sobre o plano de carreira do pessoal do magistério, de secretaria escolar e de inspeção de alunos, do pessoal de monitoria de creche e de monitoria de ensino especial da Secretaria de Educação do Município de Mariana e dá outras providências. O Monumento - Diário oficial. Disponível em:

<http://camarademariana.mg.gov.br/uploads/camara_mariana_2014/camara/legislacao/lei -complementar-139-29-04-14-plano-de-cargos-e-salarios.pdf > Acesso: 20 mai. 2017.

NOGUEIRA, Maria Alice Nogueira. A relação família-escola na contemporaneidade: fenômeno social/interrogações sociológicas. Análise Social. Lisboa, n. 176, p. 563-578, 2005.

OLIVEIRA, Dalila Andrade; ASSUNÇÃO, Ada Ávila. Condições de trabalho docente. In: OLIVEIRA, Dalila Andrade; DUARTE, Adriana Maria Cancella e VIEIRA, Lívia Fraga. DICIONÁRIO: trabalho, profissão e condição docente. Belo Horizonte: UFMG/Faculdade de Educação, 2010 CDROM.

SILVA, Santuza Amorim da; PÁDUA, Karla Cunha. Explorando narrativas: algumas reflexões sobre suas possibilidades na pesquisa. In: CAMPOS, Regina Célia Passos Ribeiro de. (Org.). Pesquisa, Educação e Formação Humana: nos trilhos da História. Belo Horizonte: Autêntica, 2010.

SOUZA, Elizeu Clementino. O Conhecimento de si: estágio e narrativa de formação e professores. Rio de Janeiro: DP\&A, 2006.

SOUZA, Elizeu Clementino. Diálogos cruzados sobre pesquisa (auto) biográfica: análise compreensiva-interpretativa e política de sentido. Educação (UFSM), v. 39, n. 1, p. 39-50, 2014.

TARDIF, Maurice; LESSARD, Claude. O trabalho docente: para uma teoria da docência como profissão de interações humanas. Petrópolis: Vozes, 2005.

TARDIF, Maurice. Saberes docentes e formação profissional. Petrópolis: Vozes, 2012. 
TEDESCO, Juan Carlos; FANFANI, Emilio Tenti. Novos docentes e novos alunos. In: Oficio de professor na América Latina e Caribe. Brasília: Fundação Víctor Civita/UNESCO, 2004. p. $67-80$.

TEIXEIRA, Inês Assunção de Castro Teixeira. Da condição docente: primeiras aproximações teóricas. Educ. Soc., Campinas, vol. 28, n. 99, p. 426-443, maio/ago. 2007. Disponível em <http://www.cedes.unicamp.br> Acesso em: 03 out. 2017.

THIN, Daniel. Para uma análise das relações entre famílias populares e escola: confrontação entre lógicas socializadoras. Revista Brasileira de Educação, v. 11, n. 32, p. 211-370, maio/ago. 2006.

WEBER, Silke. Profissionalização docente e políticas públicas no Brasil. Educ. Soc., Campinas, vol. 24, n. 85, p. 1125-1154, dezembro 2003.

WEBER, Silke. O Plano Nacional de Educação e a valorização docente: confluência do debate nacional. Cad. Cedes, Campinas, v. 35, n. 97, p. 495-515, set.-dez., 2015.

\section{SOBRE AS AUTORAS}

\section{Valdete Aparecida Fernandes Moutinho Gomes}

Mestra em Educação pela Universidade Federal de Ouro Preto (UFOP). Membro do Grupo de Pesquisa Formação e Profissão Docente (FOPROFI) do Departamento de Educação da UFOP; Professora de educação infantil da rede municipal de Mariana. E-mail: valdeteafernandes@gmail.com.

iD http://orcid.org/0000-0002-9096-9151

\section{Celia Maria Fernandes Nunes}

Doutora em Educação pela Pontifícia Universidade Católica do Rio de Janeiro (PUC-Rio). Pós-Doutora em Educação pela Universidade Federal de Minas Gerais (UFMG). Atualmente é Professora Associada da Universidade Federal de Ouro Preto (UFOP) atuando na Graduação e Pós- Graduação. Vice-líder do Grupo de Pesquisa em Formação e Profissão Docente (FOPROFI) do Departamento de Educação da UFOP. E-mail: célia@ufop.edu.br.

(iD http://orcid.org/0000-0002-2338-1876

\section{Karla Cunha Pádua}

Doutora em Educação pela Universidade Federal de Minas Gerais (UFMG). Pós-doutora em Antropologia (ICS-Universidade de Lisboa), e em Educação pela Universidade Federal de Ouro Preto (UFOP). Professora da Faculdade de Educação (FaE) e do Programa de PósGraduação em Educação (PPGE), na Universidade do Estado de Minas Gerais (UEMG), Campus de Belo Horizonte. É membro dos grupos de pesquisa Prodoc (UFMG) e Polis e Mnemosine (UEMG). E-mail: kcpadua@yahoo.com.br.

(iD http://orcid.org/0000-0003-0421-9897

Recebido em: 21 de junho de 2018 Aprovado em: 30 de setembro de 2019 Publicado em: 03 de dezembro de 2019 